\title{
Non-B HIV Type 1 Subtypes among Men Who Have Sex with Men in Rome, Italy
}

\author{
M. Giuliani, ${ }^{1,2}$ S. Montieri, ${ }^{1}$ G. Palamara, ${ }^{2}$ A. Latini, ${ }^{2}$ C. Alteri, ${ }^{3}$ C.F. Perno, ${ }^{3}$ M.M. Santoro, ${ }^{3}$ \\ G. Rezza, ${ }^{1}$ and M. Ciccozzi ${ }^{1}$
}

\section{Abstract}

An increase in the circulation of HIV-1 non-B subtypes has been observed in recent years in Western European countries. Due to the lack of data on the circulation of HIV-1 non-B subtypes among European HIV-1-infected men who have sex with men (MSM), a biomolecular study was conducted in Rome, Italy. HIV-1 partial pol gene sequences from 111 MSM individuals (76 drug naive and 35 drug experienced) were collected during the years 2004-2006. All these sequences were analyzed using the REGA HIV-1 Subtyping Tool, and aligned using CLUSTAL $X$ followed by manual editing using the Bioedit software. A BLAST search for non-B subtype sequences was also performed. Twenty-six (23.4\%) MSM were not Italians. Eight individuals (7.2\%) were diagnosed as HIV infected before 1991, 20 (18.0\%) between 1991 and 1999, and 83 (74.8\%) from 2000 to 2006. Fifteen $(15 / 111,13.5 \%)$ individuals were infected with the non-B subtype. The percentage of infection with HIV-1 non-B subtypes was $8.2 \%$ (7/85) among Italian MSM and 30.8\% (8/26) among the non-Italians (OR = $4.9595 \%$ IC: 1.40 17.87). Individuals infected with the non-B subtype were significantly younger than those infected with the HIV-1 B subtype (28 years vs. 34 years, $p=0.003$ ). The CRFs were more prevalent $(8.1 \%)$ than pure subtypes $(5.4 \%)$, which were distributed as follows: subtype C (2.6\%), subtype A1 $(1.7 \%)$, and subtype F1 (0.9\%). Major mutations conferring resistance to antiretroviral drugs (ARV) were not found among HIV-1 non-B subtype drugnaive patients but were found in two ARV-experienced individuals. The data show that viral diversity is likely increasing in a population group that had been previously characterized by the circulation of HIV-1 subtype B.

\section{Introduction}

$\mathbf{I}^{N}$ $\mathbf{N}$ THE PAST DECADE, there has been an increase in the circulation of HIV-1 non-B strains and circulating recombinant forms (CRF) in Western European countries. ${ }^{1-7}$ This has been the cause of some concern, in that although all HIV-1 subtypes appear to be equally susceptible to antiretroviral therapy ${ }^{8}$ (ARV), different HIV-1 subtypes may differ in terms of syncytiainducing capacity, ${ }^{9,10}$ rate of disease progression, pattern of ARV resistance, ${ }^{11}$ and response to possible vaccine candidates.

In Italy, the percentage of infection with non-B subtypes among HIV-seropositive people has been reported to range from $5.4 \%$ to $12.6 \%$, and it exceeds $63 \%$ among foreigners living in Italy. ${ }^{12-14}$ However, little information is available on certain population groups, such as men who have sex with men (MSM), who seem to have a high risk of infection with non-B subtypes because they are more likely than heterosexual individuals to have sex abroad, thus in countries with a high percentage of non-B subtypes, and with nonnational sexual partners. ${ }^{15,16}$ With regard to other European countries, the percentage of non-B subtypes among HIV-seropositive MSM has been reported to range between 4.0 and $11.1 \%$ in the United Kingdom, ${ }^{17,18} 12.0 \%$ in France, ${ }^{19}$ and $28.8 \%$ in Greece. ${ }^{5}$

To improve knowledge on the percentage of infection with non-B subtypes among MSM in Italy, we conducted a study among MSM with a diagnosis of HIV-1 infection who had presented to the largest sexually transmitted infections (STI) clinic in Rome, Italy. Moreover, we also estimated the prevalence of resistant strains in this MSM population, with particular attention to non-B subtypes.

\section{Materials and Methods}

\section{Study design}

One hundred and eleven (76 drug-naive and 35 drugexperienced) HIV-1-infected MSM, attending the STI/HIV

\footnotetext{
${ }^{1}$ Reparto Epidemiologia, Dipartimento Malattie Infettive, Parassitarie e Immunomediate (MIPI), Istituto Superiore di Sanità, Rome, Italy.

${ }^{2}$ S. C. Dermatologia Infettiva, Istituto Dermatovenereologico S. Gallicano (IRCCS), Rome, Italy.

${ }^{3}$ Dipartimento di Medicina Sperimentale e Scienze Biochimiche, Università degli Studi di Roma, Tor Vergata, Rome, Italy.
} 
Clinic of the Istituto Dermovenereologico San Gallicano (IRCCS) in Rome, Italy, between January 2004 and June 2006 were analyzed. All individuals were included in the clinical program for the management and treatment of HIV-1 infection.

\section{Specimen collection and DNA extraction}

HIV genotype analysis was performed on plasma samples using a commercially available kit (ViroSeq HIV-1 genotyping system; Abbott). ${ }^{20,21}$ Briefly, RNA was extracted, retrotranscribed by murine leukemia virus reverse transcriptase, and amplified with AmpliTaq Gold polymerase enzyme, using two different sequence-specific primers for 40 cycles. The full lengths of polymerase-amplified products (containing the entire protease and the first 335 amino acids of the reverse transcriptase open reading frame product) were sequenced in sense and antisense orientations by using seven different overlapping sequence-specific primers for the automated sequencer (ABI 3100). All samples from drug-naive patients were obtained after the diagnosis with a delay of 2 weeks (IQR: 1.5-4) for non-B subtype and 3 weeks (IQR: 2.5-28) for B subtypes. A genotypic test for all drug-experienced patients was performed at the time of virological failure.

The nucleotide sequences obtained in this study have been submitted to GenBank under accession numbers from FJ228036 to FJ228136.

\section{Genetic subtyping and phylogenetic analysis}

All HIV-1 partial pol gene sequences from the study participants were first analyzed using the REGA HIV-1 Subtyping Tool. ${ }^{22}$ The sequences were first aligned using CLUSTAL $X^{23}$ and then edited manually using the Bioedit software. $^{24}$ The final data set included HIV-1 clinical isolates and subtype-specific and CRF reference sequences downloaded from the HIV Los Alamos database (http:// hiv-web.lanl.gov/). A BLAST search for non-B subtype sequences was undertaken; then an alignment with reference strains, the most similar GenBank sequences for each non-B subtype plus CRFs, was performed. The best fitting nucleotide substitution model was tested with a hierarchical likelihood ratio test, using a neighbor-joining (NJ) tree, with LogDet corrected distances as the base tree. ${ }^{25} \mathrm{~A}$ maximum likelihood (ML) tree was then inferred with the selected model and MLestimated substitution parameters. The heuristic search for the best tree was performed using an NJ tree as the starting tree and the TBR branch-swapping algorithm. An NJ tree was also obtained with ML-estimated pairwise distances using the best fitting nucleotide substitution model. Calculations were performed with PAUP* software (version 4.0). ${ }^{26}$ Statistical support for specific clades was obtained with the ML-based zero branch length test for the ML tree, ${ }^{26}$ by bootstrapping (1000 replicates) for the NJ tree. The tree was rooted by outgroup rooting.

\section{Analysis of drug resistance}

Drug resistance mutations in the protease and reverse transcriptase associated with resistance to drugs used in clinical practice were also analyzed. The resistance for each drug class was defined as the presence of at least one key mutation associated with resistance to antiretroviral drugs in the reverse transcriptase and protease. ${ }^{27}$

\section{Statistical analysis}

To test the differences between HIV-1 B and non-B-infected individuals the Mann-Whitney test for the continuous variables and the Fisher exact test (or Chi squared test, as appropriate) for the categorical variables were used. $p$-values $<0.05$ were considered statistically significant. SPSS 14.0 was used to apply crosstables (Fisher's exact test and Chi squared test), correlations, and univariate analysis.

\section{Results}

\section{Patient characteristics}

Out of the 111 HIV-1-infected individuals analyzed, 26 (23.4\%) were non-Italians. With regard to the period of diagnosis of HIV-1 infection, 8 (7.2\%) individuals had been diagnosed before 1991, 20 (18.0\%) between 1991 and 1999, and $83(74.8 \%)$ from 2000 to June 2006. Among the overall population, by the NJ tree, including the pol gene sequences, $15(13.5 \%)$ clustered with non-B subtypes. Table 1 lists the characteristics of patients analyzed by comparing the $\mathrm{B}$ and non-B subtypes. The percentage of infection with non-B subtypes was $8.2 \%(7 / 85)$ among Italian MSM and $30.8 \%$ $(8 / 26)$ among non-Italian MSM. The percentage of non-B subtypes tended to increase over time: from zero for the individuals diagnosed before 1991 to $10.0 \%$ for those diagnosed in the 1990s and $15.7 \%$ among those diagnosed in the period from 2000 to June 2006 ( $p=0.44$ by the Chi squared for trend test) (data not shown). The median age was significantly lower for individuals infected with non-B subtypes [28 years (IQR: 24-34)] compared to those infected with HIV-1 B subtypes [34 years (IQR: 29-39.5)] ( $p=0.003)$. Moreover, individuals infected with non-B subtypes were significantly more likely to be non-Italian (OR $=4.9595 \% \mathrm{CI}$ : 1.40-17.87) (Table 1). Non-B subtype individuals diagnosed with HIV-1 infection were more likely to be classified as symptomatic (stages B, CDC, 1993), but the association has not reached statistical significance. Thirteen out of 76 drugnaive patients were infected with an HIV-1 non-B subtype, while 2 of 35 drug-experienced individuals were infected with an HIV-1 non-B subtype (Table 1).

The HIV-1 subtype analysis showed that among the non-B infections, CRFs were more prevalent (nine cases, $8.1 \%$ ) than pure subtypes (six cases, 5.4\%), with three CRF01_AE (2.7\%), three CRF02_AG (2.7\%), two CRF14_BG (1.8\%), and one CRF12_BF (0.9\%). Among the non-B pure subtypes, subtype $\mathrm{C}$ was the most represented (three cases, $2.6 \%$ ), followed by subtype A1 (two cases, $1.7 \%$ ) and subtype F1 (one case, $0.9 \%$ ). With regard to the country of origin of the 15 individuals with a non-B subtype, seven (46.7\%) were Italian, four (26.7\%) were from a European country, and four $(26.7 \%)$ were from outside of Europe (Table 2).

\section{Phylogenetic relationships of non-B subtype strains}

The ML pol gene tree of non-B subtypes with the more similar Blast sequences is shown in Fig. 1. Non-B isolates were distributed within six monophyletic clades and one subclade (AE subclade). The sequences coded as TRPS@05 (Italy) and BDVS@05 (the Ukraine) clustered with HIV-1 A1 Albanian and Eastern European clades respectively (9597\% identity score). The sequences DRAE@06, BLMC@04, and DLGB@06 (all from Italy; 95-97\% identity score with 
Table 1. Demographic and Clinical Selected Characteristics of 111 MSM by HiV-1 B and Non-B Subtype Infection

\begin{tabular}{|c|c|c|c|c|}
\hline & Non-B subtypes $(\mathrm{N}=15)$ & $B$ subtypes $(\mathrm{N}=96)$ & OR $(95 \% \mathrm{CI})$ & $\mathrm{p}$ value \\
\hline Age at HIV diagnosis [median (IQR)] & $28(24-34)$ & $34(29-39.5)$ & - & 0.003 \\
\hline \multicolumn{5}{|l|}{ Place of birth } \\
\hline Italy & $7(46.7)$ & $78(81.3)$ & 1 & \\
\hline Abroad & $8(53.3)$ & $18(18.7)$ & $4.95(1.40-17.87)$ & 0.003 \\
\hline \multicolumn{5}{|l|}{ Known date of seroconvertion } \\
\hline No & $11(73.3)$ & $57(59.4)$ & 1 & \\
\hline Yes & $4(26.7)$ & $39(40.6)$ & $0.53(0.12-1.97)$ & 0.338 \\
\hline \multicolumn{5}{|l|}{ HIV stage $(C D C, 1993)^{a}$} \\
\hline Asymptomatic (A1-A3) & $11(73.3)$ & $84(87.5)$ & 1 & \\
\hline Symptomatic (B1-B3) & $4(26.7)$ & $7(7.3)$ & $4.36(0.79-20.40)$ & 0.049 \\
\hline AIDS (C1-C3) & $0(0.0)$ & $5(5.2)$ & n.a. & \\
\hline \multicolumn{5}{|l|}{ Drug experience } \\
\hline No & $13(86.6)$ & $63(65.6)$ & 1 & 0.139 \\
\hline Yes & $2(13.4)$ & $33(34.4)$ & $0.29(0.03-1.43)$ & \\
\hline \multicolumn{5}{|l|}{$\mathrm{CD}^{+}{ }^{+}$cell count $^{\mathrm{a}}$} \\
\hline $\begin{array}{l}\text { Median } / \mathrm{mm}^{3} \\
\text { (IQR) }\end{array}$ & $\begin{array}{c}350 \\
(252-492)\end{array}$ & $\begin{array}{c}449 \\
(260-650)\end{array}$ & - & 0.205 \\
\hline \multicolumn{5}{|l|}{ HIV viral load ${ }^{\mathrm{a}}$} \\
\hline $\begin{array}{l}\text { Median copies/ml } \\
\text { (IQR) }\end{array}$ & $\begin{array}{c}24.000 \\
(10,000-105,000)\end{array}$ & $\begin{array}{c}50.800 \\
(13,500-170,000)\end{array}$ & - & 0.320 \\
\hline
\end{tabular}

${ }^{\mathrm{a}}$ At the first $\mathrm{HIV}-\mathrm{Ab}$ positive test.

sequences from Thailand) clustered with the AE subclade. Sequences KIPR@05 (Iceland), PGFB@07 (Italy) and VLSLFE@04 (Ecuador) clustered with the AG clade (95-96\% identity score from Western African sequences). The DSML @04 (Ethiopia), ARNL@04 (India), and MNSL@05 (Italy) sequences clustered with the C clade, showing a 94-96\% identity score with sequences from East Africa and India. The MNVC@06 sequence (Romania) showed a 94\% identity score with Eastern European sequences and clustered with the F1 clade. The sequences DSMS@05 (Italy) and KMBL@04 (Albania) clustered within the BG clade, with 98\% similarity with Cuban sequences. The DSMR@06 sequence (Brazil) clustered in the BF clade, with $94 \%$ of similarity to Argentine-Brazilian sequences. All of the non-B clades were statistically supported in both the NJ (bootstrap values $>75 \%$ ) and ML (zero branch length test $p$-value $<0.001)$ approach.

Table 2. Distribution of HIV-1 Subtypes among 111 MSM IN ROME AND COUNTRY OF ORIGIN OF HIV-1 Non-B-Infected Patients

\begin{tabular}{lcl}
\hline HIV-1 subtypes & No. (\%) & Country of origin of patient \\
\hline Pure subtype & & \\
B & $96(86.5)$ & - \\
A1 & $2(1.8)$ & Italy (2) \\
C & $3(2.7)$ & Italy, Etiopia, India \\
F1 & $1(0.9)$ & Romania \\
CRFs subtypes & & \\
CRF02_AG & $3(2.7)$ & Italy, Iceland, Ecuador \\
CRF01_AE & $3(2.7)$ & Italy (2), Ukraine, \\
CRF_BG & $2(1.8)$ & Italy, Albania \\
CRF_BF & $1(0.9)$ & Brazil \\
Total & $111(100)$ & \\
\hline
\end{tabular}

${ }^{a}$ Only for patients with HIV-1 non-B type infections.

${ }^{\mathrm{b}}$ Circulating recombinant form subtypes.

\section{Prevalence of resistance to antiretroviral drugs}

Three out of 76 naive patients carried HIV-1 strains resistant to at least one drug class (two to one class and one to two classes). None of these three individuals was infected with a non-B subtype.

The drug resistance mutations identified were the nucleotide reverse transcriptase inhibitor (NRTI) mutations $\mathrm{A} 62 \mathrm{~V}$ $(1,1.6 \%)$, T215S (1, 1.6\%), L210W (1, 1.6\%), and T215C (1, $1.6 \%)$; these last two mutations were found together with the non-NRTI (NNRTI) mutations L100I + K103N.

No major mutations were found in the protease of drugnaive individuals; in contrast, minor mutations were found in the majority of them. In non-B subtypes the polymorphisms predominantly found (frequency $\geq 75 \%$ ) were M36I and L89M (100\%), I13V (92.3\%), and H69K (76.9\%).

Twenty-two out of $35(62.9 \%)$ drug-experienced patients carried an HIV-1 strain resistant to at least one drug class (6 to one class, 12 to two classes, and 4 to three classes).

In particular, two patients infected by a non-B subtype carried resistance to two drug classes: in the first patient, infected with a CRF_BG subtype and having experienced an NRTI and PI, the NRTI mutation M184V and protease inhibitor (PI) mutations L90M and M46I were found; in the second patient, infected with a $\mathrm{C}$ subtype and having experienced an NRTI, NNRTI, and PI, the M184V and the NNRTI resistance mutations V108I, Y181C, and G190A were detected; no major mutations in the protease gene were found.

The NRTI mutation M184V was the most prevalent also in B $(14 / 33,42.4 \%)$ subtype-infected individuals; all patients carrying this mutation had taken lamivudine, with the exception of one patient infected by a B subtype. However, the tymidine analogue mutations (TAMs: M41L, D67N, K70R, L210W, T215F/Y, and K219E/Q), frequently observed in B subtype-infected patients having taken zidovudine or stavudine $(13 / 32,40.6 \%)$, were completely absent in the two 


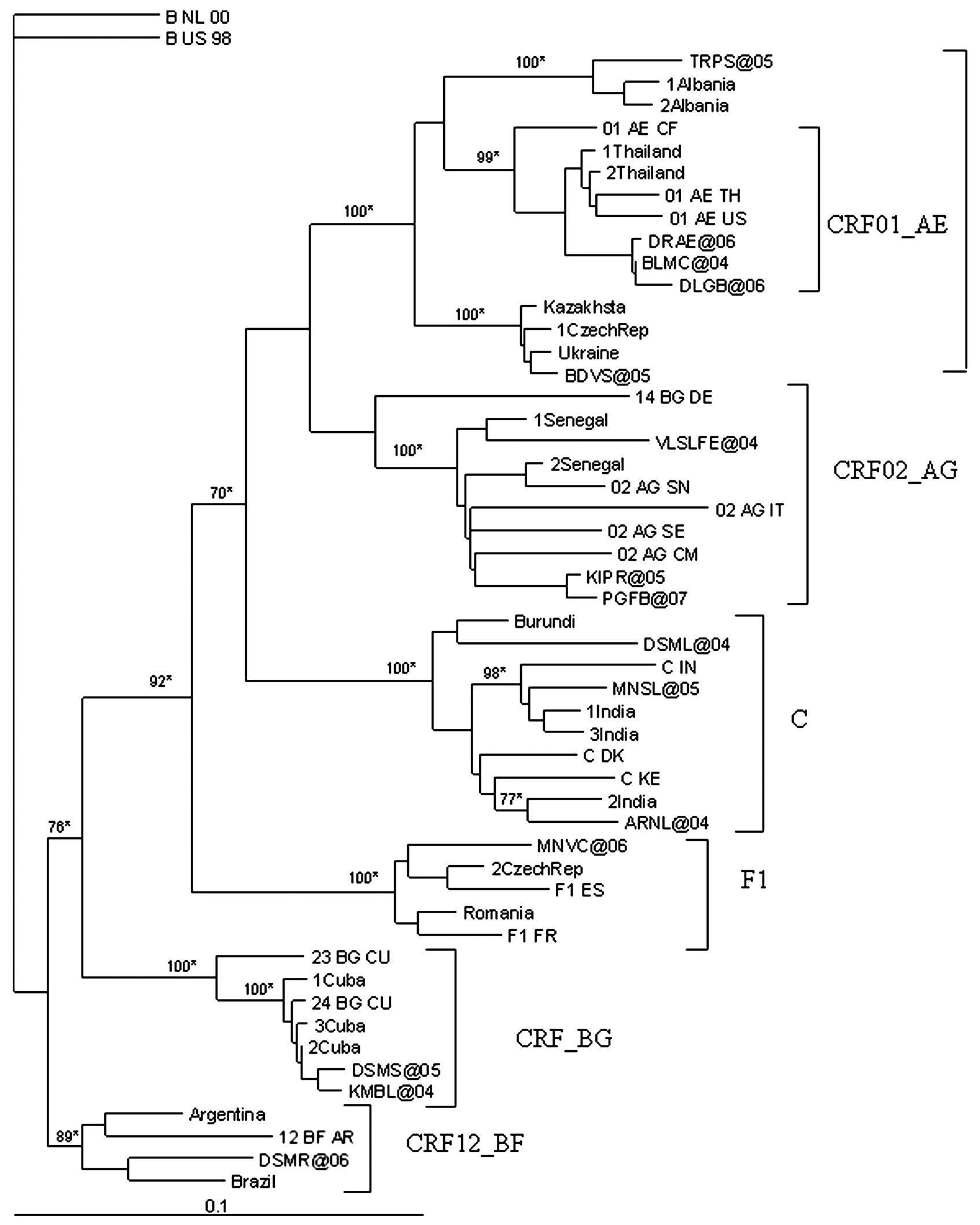

FIG. 1. Phylogenetic relationships of 15 non-B subtype strains based on 1300 nucleotide reverse transcriptase and protease regions of the HIV-1 pol gene and 34 representative strains from the Los Alamos HIV Sequence Database. Bootstrap values $<70 \%$ are not shown. The sequences of Italian MSM are indicated with a @ symbol. The scale bar indicates $10 \%$ nucleotide sequence divergence. ${ }^{*} p<0.001$ (zero length branch test). The tree was rooted by using two HIV-1B strains as the outgroup. 
patients infected with the non-B subtype, even if they had taken both these thymidine analogues.

\section{Discussion}

In Western Europe, over one-third (37\%) of the newly diagnosed cases of HIV-1 infection diagnosed in 2006 were observed in MSM. From 1999 to 2006, the number of new diagnoses of HIV-1 infection reported in MSM nearly doubled, ${ }^{28}$ simultaneously with an increase in other STIs. ${ }^{29}$ In the same period, in the United Kingdom, Germany, and Italy, a significant increase in the incidence of HIV-1 infection in cohorts of MSM was also observed..$^{30-32}$ Also in France among the MSM with a new HIV-1 diagnosis the highest proportion of recent infections $(46.0 \%)$ and an elevated percentage of non-B subtypes $(12.0 \%)$, after 2003 , have been observed. ${ }^{19}$ Nevertheless, there are relatively few data on HIV-1 genetic diversity among MSM in Europe, and most of the available data have been provided by national surveillance systems ${ }^{33,34}$ or from serosurveys of individuals attending HIV-1 screening programs in urban STI clinics. ${ }^{35}$

To contribute to our knowledge of the genetic diversity of HIV-1 among MSM, we investigated a cohort of MSM enrolled between January 2004 and June 2006 in Rome. Our results show that the proportion of individuals infected with non-B subtypes has increased over time and that in the period $2000-2006$ these individuals represented nearly $16 \%$ of all HIV-1 infections observed in our cohort.

The overall percentage of non-B subtypes in our cohort $(13.5 \%)$ is higher than the percentage reported in some northern European countries, which range from $4 \%$ to $12 \%,{ }^{17-19,34}$ although it is not even half of that observed in Greece. ${ }^{5}$ The percentage of non-B infections in our study is higher than that found in previous studies conducted in Italy among MSM, heterosexual contacts, and IDUs, ${ }^{13,36-39}$ yet it is similar to that of another study, ${ }^{40}$ reflecting the increasing circulation of non-B subytpes in the general population.

With regard to the specific non-B subtypes, the phylogenetic analysis revealed wide genetic diversity, with an intermixing between sequences from Italian and non-Italian infected individuals within six statistically supported clades, which suggests that multiple introductions of non-B subtypes are likely to have occurred. Our findings seem to suggest that in Italy, different introductions of different subtypes and CRFs are likely to have occurred from different areas of the world.

All three putative CRF01_AE sequences were from Italian MSM, though they were closely related to strains from Thailand; unfortunately, no epidemiological data (e.g., travel to Southeast Asia or to other areas of the world) were available from these individuals. This is consistent with the geographic distribution of subtype A, which is widespread in both Eastern Europe, in particular in the former USSR, ${ }^{41-43}$ Balkan countries such as Albania, ${ }^{44}$ and in Southeast Asia. ${ }^{45-47}$ The two sequences detected in Italian individuals, identified as A pure subtype, are closely related to the sequences from Balkan countries and cluster with different clades that are genetically distant; as expected, the sequence detected in the MSM from the Ukraine was similar to the representative strain; thus her infection could have been acquired in the Ukraine or from an infected individuals from this country.
Interestingly, all three individuals with a CRF-AG clade, a recombinant form that is more prevalent in West Africa, are from non-African countries (Italy, Iceland, and Ecuador). The three sequences identified as subtype $C$, although belonging to the same subtype, were harbored in different lineages. As expected, one of them, which was detected in an Ethiopian man, is closely related to the African sequences; the remaining two, which were detected in an Italian man and one Indian man, are related to the Asian sequences, yet belong to two different sublineages. Finally, the only F1 sequence was found in a man from Romania and fits with strains identified in this country, where the infection was probably acquired.

The two putative CRF14_BG sequences (from Italy and Albania) are in the same lineage and are closely related to Cuban sequences. The only sequence in the CRF12_BF clade, which was found in a Brazilian man, has the same lineage as the Brazilian sequences. ${ }^{48,49}$ The only F1 subtype was detected in a Romanian man, which is consistent with the high percentage of this subtype in this country. ${ }^{50,51}$ In summary, the existence of independent monophyletic clades implies the presence of separate transmission networks for non-B subtypes within the population analyzed.

With regard to antiretroviral drug resistance in MSM individuals, we observed substantially as low a prevalence of drug resistance in drug-naive patients as in treated patients. In particular, in drug-naive MSM individuals, resistance $(3.9 \%)$ is lower than that observed in other studies performed on the same risk class ${ }^{52-54}$ and in other studies performed on heterogeneous risk classes. ${ }^{55-58}$

The prevalence of resistance in antiretroviral-treated MSM individuals is around $60 \%$, with a decreased trend over the years 2004-2006 (data not shown), in line with that observed in recent studies; ${ }^{59,60}$ this diminished trend could explain the low prevalence of drug resistance in naive patients.

Before drawing conclusions, possible limits and biases of the study should be mentioned. First, we cannot exclude the possibility that our study population is not representative of all MSM HIV cases in Italy, since the study was conducted only in Rome. Second, only the pol gene was analyzed; thus the proportion of non-B subtypes and CRF circulation might be underestimated from our results.

At the end, this genetic pattern of HIV-1 subtypes among Italian MSM suggests that viral diversity is likely increasing in a population group that had previously been characterized by the circulation of subtype B. The introduction of different subtypes in a specific population may give rise to waves of future epidemics of unpredictable outcome, emphasizing the importance of continuing molecular surveillance of HIV-1 non-B strains, particularly among populations with a faster circulation of HIV-1 infection. Further analysis will be needed to verify the exact non-B and CRF distribution among MSM and to reconstruct accurately their evolutionary history.

\section{Acknowledgments}

The authors would like to thank Mr. Mark Kanieff for his assistance in revising the manuscript. M. Giuliani and S. Montieri have contributed equally to this paper.

\section{Disclosure Statement}

No competing financial interests exist. 


\section{References}

1. Fransen K, Buve A, Nkengasong JN, et al:: Longstanding presence in Belgium of multiple non-B HIV-1 subtypes. Lancet 1996;347:1403.

2. Leitner T, Escanilla D, Marquina S, Wahlberg J, Brostrom C, Hansson HB, Uhlen $\mathrm{M}$, and Albert J: Biological and molecular characterization of sub-types D, G, and A/D recombinant HIV-1 transmission in Sweden. Virology 1995;209: 136-146.

3. Boni J, Pyra H, Gebhardt M, Perrin L, Burgisser P, Matter L, Fierz W, Erb P, Piffaretti JC, Minder E, Grob P, Burckhardt JJ, Zwahlen $\mathrm{M}$, and Schupbach J: High frequency of non-B subtypes in newly diagnosed HIV-1 infections in Switzerland. J Acquir Immune Defic Syndr 1999;22:174-179.

4. Couturier E, Damond F, Roques P, Fleury HJ, Barin F, Brunet JB, Brun-Vezinet F, and Simon F: HIV-1 diversity in France, 1996-1998. The AC II Laboratori Network. AIDS 2000;14:289-296.

5. Paraskevis D, Magiorkinis E, Magiorkinis G, Sypsa V, Paparizos V, Lazanas $\mathrm{M}$, et al.: Increasing prevalence of HIV-1 subtype A in Greece: Estimating epidemic history and origin. J Infect Dis 2007;196:1167-1176.

6. Devereux H, Loveday C, Burke A, Dann L, Johnson M, and Philipps A: The prevalence of non-B subtypes HIV-1 in London HIV/AIDS outpatient clinic. AIDS 1999;13:142-152.

7. Holguin A, Alvarez A, and Soriano V: High prevalence of HIV-1 subtypes $G$ and natural polymorphisms at the protease gene among HIV-infected immigrants in Madrid. AIDS 2002;16:1163-1170.

8. Bannister WP, Ruiz L, Loveday C, Vella S, Zilmer K, Kjaer J, Knysz B, Phillips A, Mocroft A, and the EuroSida Study Group: HIV-1 subtypes and response to combination antiretroviral therapy in Europe. Antiviral Ther 2006;6:707-715.

9. Perez-Alvarez L, Munoz M, Delgado E, Miralles C, Ocampo A, Garcia V, Thomson M, Contreras G, Najera R, and the Spanish Group for Antiretroviral Resistance Studies in Galicia: Isolation and biological characterization of HIV-1 BG intersubtype recombinants and other genetic forms circulating in Galicia, Spain. J Med Virol 2006;78(12):1520 1528.

10. Polonis VR, de Souza MS, Darden JM, Chantakulkij S, Chuenchitra T, Nitayaphan S, Brown AE, Robb ML, and Birx DL: Human immunodeficiency virus type 1 primary isolate neutralization resistance is associated with the syncytiuminducing phenotype and lower CD4 cell counts in subtype CRF01_AE-infected patients. J Virol 2003;77(15): 8570-8576.

11. Romano L, Venturi G, Ferruzzi R, Riccio ML, Corsi P, Leoncini F, Vinattieri A, Incandela L, Valensin PE, and Zazzi M: Detection of genotypically drug-resistant HIV-1 variants and non-B subtypes in recently infected antiretroviral-naive adults in Italy. AIDS 2000;14:2204-2206.

12. Balotta C, Bagnarelli $P$, Riva C, Valenza A, Antinori S, Colombo MC, Sanpaolesi R, Violin M, Moroni M, Clementi M, and Galli M: Comparable biological and molecular determinants in HIV type 1-infected long term nonprogressors and recently infected individuals. AIDS Res Hum Retroviruses 1997;13:337-341.

13. Ciccozzi M, Montieri S, Salemi M, De Oliveira T, Dorrucci M, Sinicco A, et al.: An outbreak of HIV-1 subtype $G$ among Italian injecting drug users. AIDS 2007;9:1213-1215.

14. Buonaguro L, Tagliamonte M, Tornesello ML, Pilotti E, Casoli C, Lazzarin A, Tambussi G, Ciccozzi M, Rezza G,
Buonaguro FM, and the Italian Concerted Action on PHI Treatment: Screening of HIV-1 isolates by reverse hetero duplex mobility assay and identification of non-B subtypes in Italy. J Acquir Immune Defic Syndr 2004;37(2):1295-1306.

15. Elford J, Bolding G, Davis M, Sherr L, and Hart G: Webbased behavioural surveillance among MSM: A comparison of online and offline samples in London, UK. J Acquir Immune Defic Syndr 2004;35:421-426.

16. Mercer CH, K Fenton A, Welling K, Copas AJ, Erens B, and Johnson AM: Sex partner acquisition while overseas: Results from a British national probability survey. Sex Transm Infect 2007;83:517-522

17. Chawla A, Murphy G, Donnelly C, Booth CL, Johnson M, Parry JV, et al.: Human immunodeficiency virus (HIV) antibody avidity testing to identify recent infection in newly diagnosed HIV type 1 (HIV-1)-seropositive persons infected with diverse HIV-1 subtypes. J Clin Microbiol 2007;45:415-420.

18. Aggarwal I, Smith M, Tatt ID, Murad S, et al.: Evidence of onward transmission of HIV-1 non-B subtype strains in the United Kingdom. J Acquir Immune Defic Syndr 2006;41: 201-209.

19. Semaille C, Barin F, Cazein F, Pillonel J, Lot F, et al:: Monitoring the dynamics of the HIV epidemic using assays for recent infection and serotyping among new HIV diagnoses: Experience after 2 years in France. J Infect Dis 2007;196: 377-383.

20. Ceccherini-Silberstein F, Erba F, Gago F, Bertoli A, Forbici F, Bellocchi MC, Gori C, D'Arrigo R, Marcon L, Balotta C, Antinori A, D'Arminio Monforte A, and Perno CF: Identification of the minimal conserved structure of HIV-1 protease in the presence or absence of drug pressure. AIDS 2004;18:11-19.

21. Perno CF, Cozzi-Lepri A, Balotta C, Forbici F, Violin M, Bertoli A, Facchi G, Pezzati P, Cadeo G, Tositti G, Pasquinucci S, Pauluzzi S, Scalzini A, Salassa B, Vincenti A, Phillips AN, Dianzani F, Apice A, Angarano G, Monno L, Ippolito G, Moroni M, and D'Arminio Monforte A: Secondary mutations in the protease region of human immunodeficiency virus and virological failure in drug-naïve patients treated with protease inhibitor based therapy. J Infect Dis 2001; 184:983-991.

22. De Oliveira T, Deforche $\mathrm{K}$, Cassol S, et al.: An automated genotyping system for analysis of HIV-1 and other microbial sequences. Bioinfomatics 2005;21:3797-3800.

23. Thompson JD, Gibson TJ, Plewniak F, Jeanmougin F, and Higgins DG: CLUSTAL_X windows interface: Flexible strategies for multiple sequence alignment aided by quality analysis tools Nucleic Acids Res 1994;25:4876-4882.

24. Hall TA: Bioedit: A user-friendly biological sequence alignment editor and analysis program for Windows 95/98 NT. Nucleic Acids Symp Ser 1999;41:95-98.

25. Swofford D and Sullivan J: Phylogeny inference based on parsimony and other methods with PAUP*. In: The Phylogenetic Handbook - a Practical Approach to DNA and Protein Phylogeny (Salemi M, Vandamme AM, eds.). Cambridge University Press, New York, 2003, pp. 160-206.

26. Swofford DL: PAUP Phylogenetic Analysis Using Parsimony (*and other methods), Version 4.0. Sinauer Associates, Sunderland, MA, 2002. HIV/AIDS Surveillance in Europe: End-year report 2005, No. 73.

27. Johnson VA, Brun-Vezinet F, Clotet B, et al.: Update of the drug resistance mutations in HIV-1: Spring 2008. Top HIV Med 2008;16:62-68. 
28. Herida M, Alix J, Devaux I, Likatavicius G, Desenclos JC, Matic S, Ammon A, and Nardone A: HIV/AIDS in Europe: Epidemiological situation in 2006 and a new framework for surveillance. Euro Surveill 2007;12(11):E071122.1.

29. Dougan S, Evans BG, and Elford J: Sexually transmitted infections in Western Europe among HIV-1 positive men who have sex with men. Sex Transm Dis 2007;34:783-790.

30. Rice B, Nardone A, Gill N, and Delpech V: Continuing high levels of HIV diagnoses in men who have sex with men in the United Kingdom. Euro Surveill 2008;13(14):pii 8085.

31. Marcus U, Voss L, Kollan C, and Hamouda O: HIV incidence increasing in MSM in Germany: Factors influencing infection dynamics. Euro Surveill 2006;11(9):157-160.

32. Giuliani M, Di Carlo A, Palamara G, Dorrucci M, Latini A, Prignano G, Stivali G, and Rezza G: Increased HIV incidence among men who have sex with men in Rome. AIDS 2005;13: 1429-1431.

33. Lot F, Semaille C, Cazein F, Barin F, Pinget R, Pillonel J, and Desenclos JC: Preliminary results from the new HIV surveillance system in France. Euro Surveill 2004;9:34-37.

34. Yirrell DL, Shaw L, Burns SM, Cameron SO, Quigg M, Campbell E, and Goldberg D: HIV-1 subtype in Scotland: The establishment of a national surveillance system. Epidemiol Infect 2004;132:693-698.

35. Dukers NH, Fennema HS, van der Snoek EM, Krol A, Geskus RB, Pospiech M, Jurrians S, van der Meijden WI, Couthinho RA, and Prins M: HIV incidence and HIV testing behavior in men who have sex with men: Using three incidence sources, The Netherlands, 1984-2005. AIDS 2007; 21(4):491-499.

36. Tagliamonte M, Vidal N, Tornesello ML, Peeters M, Buonaguro FM, and Buonaguro L: Genetic and phylogenetic characterization of structural genes from non-B HIV-1 subtypes in Italy. AIDS Res Hum Retroviruses 2006;22(10):10451051.

37. Monno L, Brindicci G, Lo Caputo S, Punzi G, Scarabaggio T, Riva C, Di Bari C, Pierotti P, Saracino A, Lagioia A, Mazzotta F, Balotta C, and Angarano G. HIV-1 subtypes and circulating recombinant forms (CRFs) from HIV-infected patients residing in two regions of central and southern Italy. J Med Virol 2005;75(4):483-490.

38. Balotta C, Facchi G, Violin M, Van Dooren S, Cozzi-Lepri A, Forbici F, Bertoli A, Riva C, Senese D, Caramello P, Carnevale G, Rizzardini G, Cremonini L, Monno L, Rezza G, Perno CF, Ippolito G, D'Arminio-Monforte A, Vandamme AM, Moroni M, and the ICONA Study Group: Increasing prevalence of non-clade B HIV-1 strains in heterosexual men and women, as monitored by analysis of reverse transcriptase and protease sequences. J Acquir Immune Defic Syndr 2001;27(5):499-505.

39. Buonaguro L, Tagliamonte $\mathrm{M}$, Tornesello ML, and Buonaguro FM: Genetic and phylogenetic evolution of HIV-1 in a low subtype heterogeneity epidemic: The Italian example. Retrovirology 2007;4:34.

40. Baldanti F, Paolucci S, Ravasi G, Maccabruni A, Moriggia A, Barbarini G, et al.: Changes in circulation of B and nonB HIV strains: Spotlight on a reference centre for infectious diseases in Northern Italy. J Med Virol 2008;80(6): 947-952.

41. Smolskaya T, Liitsola K, Zetterberg V, Golovanova E, et al.: HIV epidemiology in the Northwestern Federal District of Russia: Dominance of HIV type 1 subtype A. AIDS Res Hum Retroviruses 2006;22(11):1074-1080.
42. Saad MD, Aliev Q, Botros BA, et al.: Genetic forms of HIV type 1 in the former Soviet Union dominate the epidemic in Azerbaijan 2006. AIDS Res Hum Retroviruses 2006;22(8): 796-800.

43. Zarandia M, Tsertsvadze T, Carr JK, Nadai Y, Sanchez JL, and Nelson AK: HIV-1 genetic diversity and genotyping drug susceptibility in the Republic of Georgia. AIDS Res Hum Retroviruses 2006;22(5):470-476.

44. Ciccozzi M, Gori C, Boros S, et al.: Molecular diversity of HIV in Albania. J Infect Dis 2005;192:475-479.

45. Kato S, Saito R, and Hiraishi Y: Differential prevalence of HIV type 1 subtype B and CRF01_AE among different sexual transmission groups in Tokyo, Japan, as revealed by subtype-specific PCR. AIDS Res Hum Retroviruses 2003; 19:1057-1063.

46. Lan NT, Recordon-Pinson P, Hung PV, et al:: HIV type 1 isolates from 200 untreated individuals in Ho Chi Minh City (Vietnam): ANRS 1257 Study. Large predominance of CRF01_AE and presence of major resistance mutation to antiretroviral drugs. AIDS Res Hum Retroviruses 2003;19: 925-928.

47. Wichukchinda N, Shiino $\mathrm{T}$, Srisawat J, et al.: Heterosexual transmission of novel CRF01 AE and subtype B recombinant forms of HIV type 1 in Northern Thailand. AIDS Res Hum Retroviruses 2005;21:734-738.

48. Cavalcanti AM, Lacerda HR, de Brito AM, Pereira S, Medeiros D, and Oliveira S: Antiretroviral resistance in individuals presenting therapeutic failure and subtypes of the human immunodeficiency virus type 1 in the Northeast Region of Brazil. Mem Inst Oswaldo Cruz 2007;7:785792.

49. Varella RB, Ferreira SB, de Castro MB, Zalis MG, and Tavares MD: Human immunodeficiency virus type 1 protease and reverse transcriptase mutation patterns among treatment-naive patients in different stages of infection in Rio de Janeiro, Brazil. J Med Virol 2007;8:1033-1039.

50. Apetrei C, Necula A, Holm-Hansen C, Loussert-Ajaka I, Pandrea I, Cozmei C, Streinu-Cercel A, Pascu FR, Negut E, Molnar G, Duca M, Pecec M, Brun-Vézinet F, and Simon F: HIV-1 diversity in Romania. AIDS 1998;9:1079-1085.

51. Chiţu V, Diaconu CC, Veliceasa D, Ruţa ` S, Grancea C, Târdei G, and Cernescu CE: Dynamics of the HIV-1 variability in adults from Bucharest, 1992-1998. Rom J Virol 1999;50:43-51.

52. Zhang X, Li S, Li X, et al.: Characterization of HIV-1 subtypes and viral antiretroviral drug resistance in men who have sex with men in Beijing, China. AIDS 2007;21(Suppl. 8): S59-65.

53. Eshleman SH, Husnik M, Hudelson $S$, et al:: Antiretroviral drug resistance, HIV-1 tropism, and HIV-1 subtype among men who have sex with men with recent HIV-1 infection. AIDS 2007;21:1165-1174.

54. Gorbach PM, Drumright LN, Javanbakht M, et al.: Antiretroviral drug resistance and risk behavior among recently HIV-infected men who have sex with men. J Acquir Immune Defic Syndr 2008;47:639-643.

55. Lapadula G, Izzo I, Gargiulo F, et al.: Updated prevalence of genotypic resistance among HIV-1 positive patients naïve to antiretroviral therapy: A single center analysis. J Med Virol 2008;80:747-753.

56. Weinstock HS, Zaidi I, Heneine W, et al.: The epidemiology of antiretroviral drug resistance among drug-naive HIV-1infected persons in 10 US cities. J Infect Dis 2004;189:21742180. 
57. Wensing AM, van de Vijver DA, Angarano G, et al.: Prevalence of drug-resistant HIV-1 variants in untreated individuals in Europe: Implications for clinical management. J Infect Dis 2005;192:958-966.

58. Yerly S, von Wyl V, Boni J, et al.: Transmission of HIV-1 drug-resistance in Switzerland: A 10-year molecular epidemiology survey. Antiviral Ther 2007;21:2223-2229.

59. Di Giambenedetto S, Colafigli M, Pinnetti C, et al: Genotypic resistance profile and clinical progression of treatment-experienced HIV type 1-infected patients with virological failure. AIDS Res Hum Retroviruses 2008;24: 149-154.

60. Vercauteren J, Deforche K, Theys K, et al.: The incidence of multidrug and full class resistance in HIV-1 infected patients is decreasing over time (2001-2006) in Portugal. Retrovirology 2008;1:5-12.
Address reprint requests to: Massimo Giuliani

Reparto Epidemiologia Istituto Superiore di Sanità

Viale Regina Elena, 299

00161 Rome, Italy

E-mail: giuliani@iss.it

Massimo Ciccozzi Reparto Epidemiologia Istituto Superiore di Sanità

Viale Regina Elena, 299

00161 Rome, Italy

E-mail: massimo.ciccozzi@iss.it 